\title{
Retinal pigment epithelium and choroid translocation in patients with exudative age-related macular degeneration: long-term results
}

\author{
Kristel Maaijwee • Heinrich Heimann • Tom Missotten • \\ Paul Mulder • Antonia Joussen • Jan van Meurs
}

Received: 27 February 2007 / Revised: 27 April 2007 / Accepted: 7 May 2007 / Published online: 12 June 2007

(C) Springer-Verlag 2007

\begin{abstract}
Background To study the results of the translocation of a free autologous retinal pigment epithelium (RPE)-choroid graft after removal of a subfoveal choroidal neovascular membrane in patients with exudative age-related macular degeneration (AMD), and to determine whether preoperative variables may predict visual outcome at 1 year after surgery. Methods Prospective interventional case series of 84 eyes of 83 consecutive eligible patients with exudative AMD
\end{abstract}

K. Maaijwee $\cdot$ T. Missotten $\cdot$ J. van Meurs

Department of Vitreoretinal Surgery, the Rotterdam Eye Hospital,

Rotterdam, The Netherlands

H. Heimann

St. Paul's Eye Unit, Royal Liverpool University Hospital,

Liverpool, UK

P. Mulder

Department of Epidemiology \& Biostatistics,

Erasmus Medical Center,

Rotterdam, The Netherlands

A. Joussen

Department of Ophthalmology, University of Düsseldorf,

Düsseldorf, Germany

J. van Meurs

Erasmus University Rotterdam,

Rotterdam, The Netherlands

K. Maaijwee $(\triangle)$

Schiedamse Vest 180,

3011 BH Rotterdam, The Netherlands

e-mail: kmaaijwee@hotmail.com with a minimal follow-up of 1 year after surgery. Of this group, 45, 24 and 11 patients reached a follow-up of respectively 2,3 and 4 years. Pre- and postoperative evaluation included ETDRS visual acuity (VA), fixation testing and color fundus photography. Preoperative fluorescein angiograms were assessed by masked readers for lesion size, size of hemorrhage and lesion composition according to the MPS criteria. The relationship between lesion composition adjusted for preoperative delay and VA, lesion size, percentage of blood, and visual outcome at 1 year after surgery was analyzed.

Results The mean VA (logMAR) improved slightly at 1 and 2 years $(0.89, \Delta=-0.06), 3$ years $(0.79, \Delta=-0.16)$ and 4 years $(0.74, \Delta=-0.21)$ after surgery. Five patients had a preoperative VA better than $20 / 80$, compared to 19 out of 84 , six out of 45, four out of 24 and two out of 11 after 1, 2, 3 and 4 years respectively. Fixation was located on the graft in 62 patients $(74 \%)$ up to the last examination. Predominantly classic and occult lesions had a significant better prognosis than minimally classic or hemorrhagic ( $\geq 50 \%$ blood) lesions. Retinal detachment occurred in seven patients; two caused by rhegmatogenous detachment and five caused by proliferative vitreoretinopathy. In 11 eyes, a recurrent or persisting neovascular membrane was observed.

Conclusion An autologous free RPE-choroid graft may stabilize or improve vision in patients with exudative AMD up to 4 years after surgery.

Keywords RPE-choroid translocation - Age-related macular degeneration $\cdot$ Long-term results 


\section{Introduction}

In industrialized countries, age-related macular degeneration (AMD) is the principal cause of irreversible legal blindness in elderly persons $[3,16,30]$. In the exudative form, the most promising treatment modality are pharmacological agents. Recently, anti-VEGF treatment has for the first time showed visual improvement $[10,13,31]$. Surgical approaches have also been reported, generally as pilot studies.

Submacular CNV removal was found ineffective in preserving or regaining useful vision $[7,11,12,25]$. The functional restoration achieved in some AMD patients after macular translocation with a $360^{\circ}$ retinotomy proved the potential of creating a fresh surface of functioning RPE cells $[8,27,28]$. A tilted image in successfully operated patients, complex surgery and numerous complications, however, remained drawbacks of this technique.

Several strategies have been reported to reconstitute the submacular RPE after CNV extraction, with transplantation of sheets of homologous fetal RPE and suspensions of autologous iris pigment epithelium or RPE cells. However, there is a lack of demonstrable presence or function of these transplants in patients $[4,5,23]$. Peyman et al. first reported the translocation of a free full-thickness autologous graft consisting of RPE, Bruch's membrane, choriocapillaris and choroid taken from the paramacular region in one patient [29]. This approach was refined in Moorfield's Eye Hospital $[19,32]$. To minimize trauma to the macular area, we pioneered a technique to cut out the graft from the midperiphery $[22,24]$. The feasibility of this technique has recently been confirmed in other pilot studies $[15,20]$.

The present report concerns the results of the transplantation of a free RPE-choroid graft harvested from the midperiphery in a larger group of patients up to 4 years after surgery. We also wished to study whether we could identify preoperative conditions predictive for visual outcome.

\section{Patients and methods}

\section{Patients}

We report the data of 84 eyes of 83 consecutive eligible patients with exudative AMD (one patient had both eyes treated). Patients were eligible if they had a subfoveal CNV membrane, with or without submacular blood, not treatable by other modalities available at that time in our hospital (laser, photodynamic therapy from May 2003 onwards) and before the introduction of Avastin (bevacizumab). Exclusion criteria for surgery included a $\mathrm{CNV}$ with an etiology other than AMD (e.g. angioid streaks), a visual acuity (VA) of $>20 / 80$ and a history of symptomatic visual loss for more than 6 months.
The Institutional Review Board of the Rotterdam Eye Hospital approved the study; written informed consent was obtained from all patients in accordance with the ethical standards laid down in the Declaration of Helsinki. The first patient was included in October 2001, and the censoring date was June 2006.

Preoperative examination included best-corrected ETDRS VA (Snellen and $\operatorname{logMAR}$ equivalents), dilated funduscopy, fluorescein angiography (FA) or indocyanine green (ICG) angiography. Postoperative visits were scheduled at 1, 3 and 6 weeks, at 3, 6, 9, 12, 18 months, as well as 2,3 and 4 years. During each visit, best corrected ETDRS VA testing was performed.

Foveal fixation and retinal sensitivity over the graft were determined in all patients with biomicroscopy. In addition, depending on the temporary availability of this device in our hospital, fundus micro perimetry MP-1 (Nidek, Padova, Italy) was performed in selected patients to determine retinal sensitivity and fixation stability over the graft. Fixation was classified as stable, relatively unstable or unstable [9].

Every year after surgery, color fundus pictures were taken. The graft was monitored with optical coherence tomography (OCT) by 6-mm radial scans (Zeiss stratum OCT, model 3000, Carl Zeiss, Jena, Germany).

\section{Grading of preoperative images}

Masked readers (HH and TM) independently assessed the preoperative stereo color fundus photographs and FAs. Pictures were imported into image analysis software (ImageJ for Mac OC X, National Institute of Health, Bethesda, MD, USA). The fundus pictures and FA were used for identification of disc area (DA), lesion size (in DA; all lesion components taken together) and composition, and size of hemorrhage (in DA and \% of lesion). Lesion composition (predominantly classic, minimally classic or occult) was classified with FA according to the Macular Photocoagulation Study (MPS) [21]. If a lesion was covered with an extensive hemorrhage $(\geq 50 \%$ of the lesion), the lesion was labeled a "hemorrhagic lesion".

\section{Surgery}

After the induction of a posterior vitreous detachment, a complete vitrectomy was performed.

The choroidal membrane was removed from the subretinal space with a Thomas subretinal forceps through a paramacular retinotomy in the temporal raphe (Fig. 1a). After circular heavy diathermia in the midperiphery at the 12 o'clock position and removal of the retina within the diathermia marks, vitreous scissors were used to cut a fullthickness graft of RPE-choroid of approximately 1.5-2.5× 
Fig. 1 Schematic overview of the translocation of a free autologous full-thickness RPE-choroid graft in patients with exudative AMD. a Extraction of the subfoveal neovascular membrane. b The graft is cut out and prepared from the sclera in an area demarcated with coagulations in the midperiphery. c Loading of the graft on a spatula or grasped with forceps (not shown in figure). d Insertion of the graft in the submacular space while injecting perfluorocarbon liquid (PFCL). Medical art work by Dr. Jessica Leenen

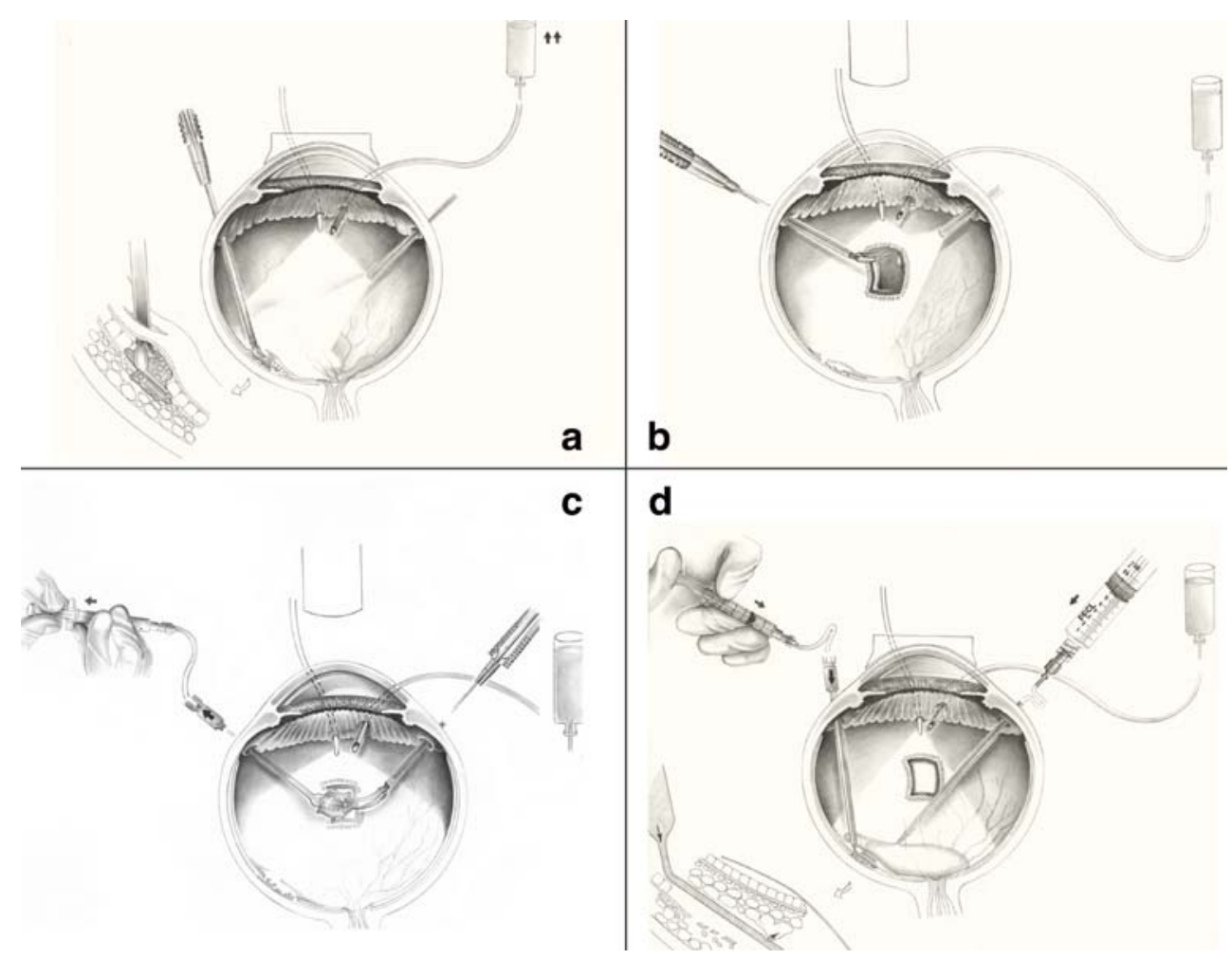

2-3 mm (Fig. 1b). The graft was loaded onto an aspirationreflux spatula (Fig. 1c) (Dutch Ophthalmic Research Center (DORC), Zuidland, The Netherlands) and repositioned under the macula through the existing paramacular retinotomy (Fig. 1d). Perfluorocarbon liquid (PFCL) was injected to keep the graft in place and facilitate the release of the graft when retracting the instrument. The midperipheral donor site was surrounded with laser coagulation followed by a silicone oil tamponade. In a second procedure, approximately 3 months later, the silicone oil was removed. Lensectomy and insertion of an intraocular lens (IOL) were performed during the first or second surgery in phakic patients. One vitreoretinal surgeon (JvM) performed all surgeries.

\section{Statistical analysis}

Analysis of covariance (ANCOVA) was used to analyze the relation between the four lesion composition groups (minimally classic, predominantly classic, occult or hemorrhagic), adjusted for the following variables: 1) preoperative delay (i.e. time between onset of symptoms and surgery), 2) preoperative VA, 3) lesion size, and 4) percentage of blood, and the outcome variable: postoperative VA at 1 year after surgery. The postoperative VA was reported as $\operatorname{logMAR}$ and Snellen equivalents, or less than two or three ETDRS lines loss.

All analyses were performed using SPSS (Windows version 12.0; SPSS Inc., Chicago, USA).

\section{Results}

Completion of scheduled examinations

Of 92 consecutive AMD patients treated with an RPEchoroid graft translocation for $\geq 1$ year after initiation of this study, 83 patients ( 84 eyes) (91\%) completed the 1-year follow-up. Fifty-seven of these 83 patients had reached the 2-year follow-up. Complete data were available in 45 of these 57 patients $(79 \%)$. The 3-year follow-up was completed in 24 out of 27 patients (89\%), and all 11 patients completed the 4-year follow-up.

Reasons for loss of follow-up were: deceased of unrelated causes $(n=7)$, physically unable to return for the follow-up $(n=8)$ and loss of contact $(n=8)$.

The visual outcomes of the patients lost during followup are incorporated in the Kaplan-Meier plot (Fig. 3).

\section{Baseline characteristics}

The age of the 83 patients (49 females and 34 males) was $79 \pm 8$ (mean \pm SD) years (range $57-95$ years). The preoperative delay in the operated eye $(n=84)$ ranged from 1 week to 6 months (mean of 10 weeks). Patients with a hemorrhagic lesion ( $\geq 50 \%$ blood) had a mean delay of 5 weeks after onset of symptoms, compared to 10 to 14 weeks in the other groups.

Forty patients used anticoagulants. They were asked to discontinue these medications 2 weeks prior to surgery. 
Twenty-two patients were initially pseudophakic. None of the patients remained phakic.

Grading of preoperative images

The preoperative FAs together with a fundus image were available in 68 (out of 84 ) eyes. FA lacked in 16 patients: erroneously, in seven patients only an ICG was obtained because of macular hemorrhages. In eight patients, FAs were made and evaluated before surgery, but were lost before evaluation by our masked readers; and in one patient the FA was made 6 months before surgery and therefore excluded. The lesions of these 16 eyes were not analyzed.

The two independent masked readers classified the FA differently in seven eyes, but consensus was reached after consultation. According to the MPS criteria, nine patients had a predominantly classic, 14 a minimally classic, 18 an occult subfoveal neovascularization and 27 were classified as hemorrhagic lesion ( $\geq 50 \%$ blood). The size of the total lesion varied from 1.5 to 72 MPS disk areas (DA)(mean 10 DA). Subretinal blood was present in all but six (out of 68 available) angiograms.

\section{Visual outcome}

Mean preoperative VA was $0.95 \log$ MAR (range $1 / 300$ to 20/80), and $0.89 \operatorname{logMAR}$ (range $1 / 300$ to 20/32) after 1 and 2 years, $0.79 \operatorname{logMAR}$ (range $1 / 60$ to $20 / 25$ ) after 3 years, and $0.74 \operatorname{logMAR}$ (range $20 / 800$ to $20 / 32$ ) after 4 years. This represents no average change in ETDRS lines. Five patients had a preoperative vision of $20 / 80$, whereas

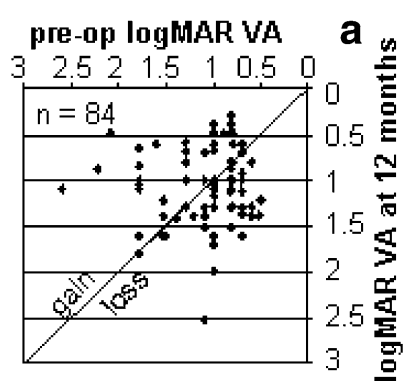

pre-op loghAR WA

$\begin{array}{lllllll}3 & 2.5 & 2 & 1.5 & 1 & 0.5 & 0\end{array}$

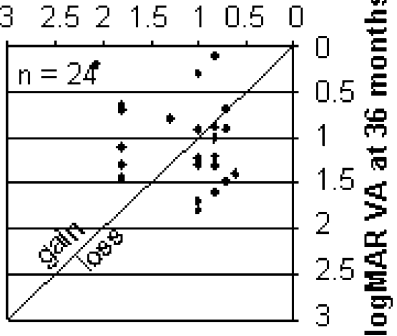

Fig. 2 Preoperative versus postoperative visual acuity (logMAR). a-d At 1, 2, 3 and 4 years after surgery $(n=84,45,24$ and 11 respectively). Data points above the diagonal line indicate patients with visual improvement

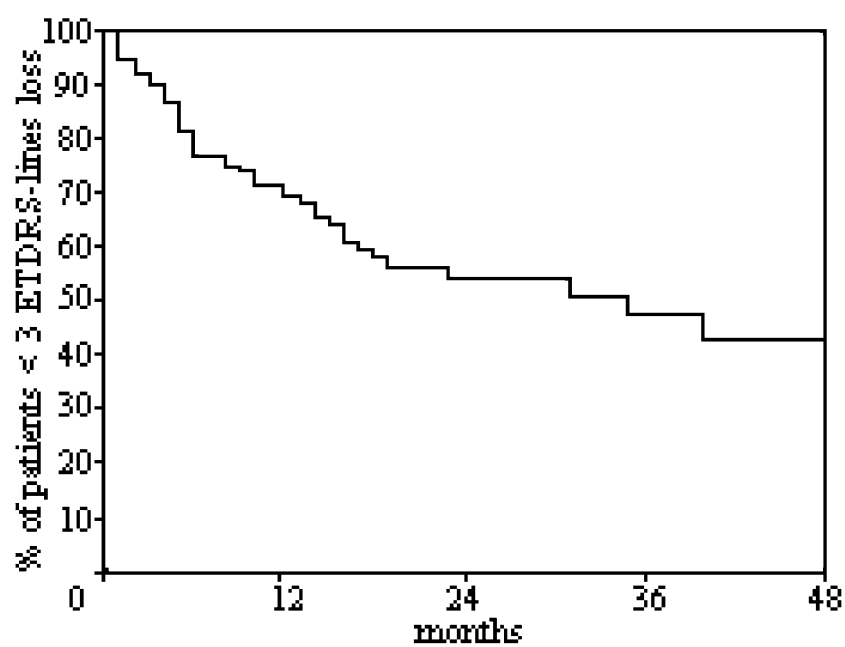

Fig. 3 Kaplan-Meier plot of percentage of patients $(n=92)$ who had $<3$ ( $\leq 2)$ ETDRS-lines loss. The patients lost within the 4-year followup are included

19 out of 84 patients had a VA of $20 / 80$ or better after 1 year, and six out of 45 , four out of 24 and two out of 11 after 2, 3 and 4 years respectively (Fig. 2).

A loss of $\leq 2(<3)$ ETDRS lines was observed in $76 \%$ (64 out of 84 ) to $82 \%$ (9 out of 11) from 1 to 4 years after surgery respectively (Fig. 3).

The mean VA at 1 year after surgery in the four lesion composition groups was $1.09 \log$ MAR in the minimally classic, $0.96 \log$ MAR in the hemorrhagic, $0.82 \log$ MAR in the predominantly classic and $0.77 \log$ MAR in the occult lesion group.

If a last observation carried forward method was applied to these data $(n=92)$ (to correct for patients lost to followup), mean VA was 0.91, 0.93, 0.92 and $0.93 \log$ MAR at 1 , 2, 3 and 4 years after surgery respectively.

Foveal fixation on the graft viewed by biomicroscopy was present in $74 \%$ (62 out of 84 ) of the eyes up to the last examination. Twelve patients lost their fixation over the graft during follow-up, associated with a decrease in VA (mean $1.48 \log$ MAR).

Retinal sensitivity could be demonstrated over the graft in 16 of 19 patients examined with the NIDEK MP-1 (Fig. 4). Nine of these patients had fixation over the graft; three of them were graded as stable and six as relatively unstable. Of the ten eyes without fixation over the graft at the time of examination with the MP-1 microperimeter, six eyes gained fixation during follow-up.

Imaging

Postoperative angiograms were performed in 27 patients; in 14 both FA and ICG, in eight FA only and in five ICG only. Indications for a postoperative angiography were suspicion of a central retinal vein occlusion $(n=1)$ or recurrent/ persistent $\mathrm{CNV}(n=17)$, an unexplained loss of VA $(n=2)$, 
research purposes $(n=4)$ and suspicion of pathology in the fellow eye $(n=3)$.

Early fluorescence of the graft was seen in 21 of the 22 FAs obtained from 1 month to 4 years after surgery (Fig. 4). In 10 of 19 ICGs, obtained from 1 to 27 months after surgery, perfusion of the parallel oriented graft vasculature could be identified in the early phases of the ICG (Fig. 4). In seven patients without visualization of the graft vasculature with ICG, FA showed early fluorescence (in one patient the FA was not performed). The graft that lacked fluorescence with early FA also had no signs of choroidal graft perfusion with ICG.

The graft had a brown, velvety appearance in 60 eyes. In three patients the graft had a convex shape, in two eyes one side was folded, in two eyes the graft was small $(<1 \mathrm{DA})$, and in two patients the graft had become fibrotic. In these nine patients, VA was $\leq 20 / 250$ (mean 20/640) after 1 year. Irregular accumulation of hyperpigmentation at the margins or near the graft, and sometimes on the graft, could be seen in 59 patients, starting from 3 months after surgery (mean 7 months) and increasing in time (Fig. 4). Except for this
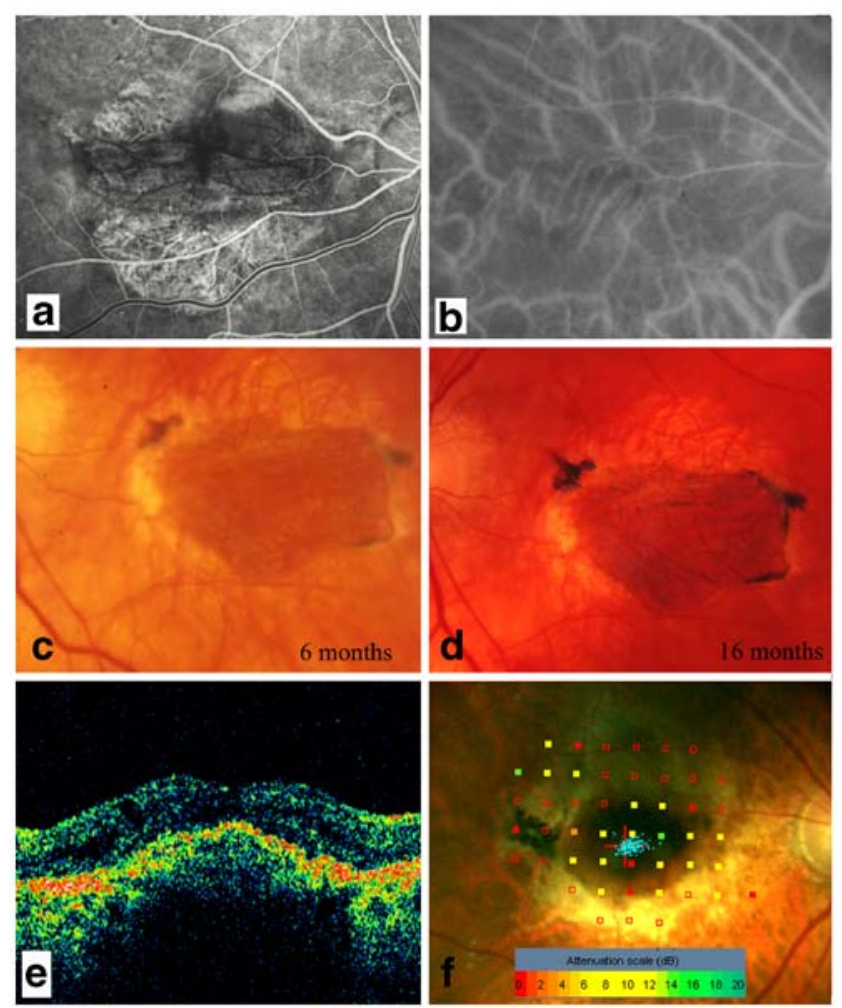

Fig. 4 Imaging of a free RPE-choroid graft. a Fluorescein angiography. The graft fluorescence emerges simultaneously with the surrounding fundus in the early phase. b Indocyanine green angiography reveals perfusion of the parallel oriented vessels of the graft. c-d Fundus images with typical accumulations of pigmentation alongside and on the graft increasing over time. e OCT image. The retina overlying the graft has a layered structure, foveal depression, present but suboptimal photoreceptor layer. f Microperimetry shows function on the graft hyperpigmentation, the position, size and shape of the graft did not change during follow-up.

OCT of the graft was performed in 55 patients. The graft RPE layer was observed in all 55 patients up to 4 years after surgery (Fig. 4). The photoreceptor layer was absent in $14(25 \%)$ patients with a mean VA of $1.05 \operatorname{logMAR}$, and present but suboptimal in $41(75 \%)$ with a mean VA of 0.77 logMAR $(P=0.012)$. In $16(29 \%)$ patients, cystic spaces were present at time of OCT imaging.

\section{Complications during surgery}

A complete posterior vitreous detachment (PVD) was present in only ten patients at the start of surgery; in all others a PVD had to be induced, with remaining hyaloid (as a result of hyaloidal schizis) covering the retina in 42 patients.

Complications during surgery occurred in $17 \%$ (14 out of 84) of the patients and consisted of a CNV-membrane attached to the retina $(n=1)$, a large choroidal defect after removing the CNV-membrane $(n=1)$, damage to the papillomacular bundle $(n=1)$, trauma of the subfoveal choroid with bleeding ( $n=6$, two of which were caused by manipulation of the graft during repositioning), tearing of the retinotomy with bleeding $(n=2)$, a peripheral retinal tear $(n=1)$, a retinal detachment $(n=1)$ and loss of the graft through the sclerotomies with the need to prepare a second graft $(n=3)$.

The main problems encountered were failure of the subfoveal release of the graft $(n=18)$, an inadequate positioning or incomplete flattening of the graft $(n=56)$, which was partly folded or wrinkled underneath the fovea. In 12 of these cases the graft had to be removed and was reinserted. To optimize the position or to unfold the graft, reposition by manipulating the subfoveal graft was performed in these 74 patients $(88 \%)$.

\section{Postoperative complications}

After surgery, a recurrent or persistent $\mathrm{CNV}$ membrane was observed in 11 patients (13\%) (range 2 to 27 months after surgery). Ten CNV membranes were closed by thermal laser treatment and recently (June 2006) in one patient, Avastin (bevacizumab) was injected. In these 11 recurrences, vision dropped to counting fingers in seven patients, three remained stable after treatment (VA of 20/100) and one patient even improved to a VA of 20/80, with 20/125 at the last examination 2 years after surgery.

Retinal detachment (RD) occurred in seven patients (8\%); five due to proliferative vitreoretinopathy (PVR) and two with a rhegmatogenous cause. One rhegmatogenous$\mathrm{RD}$ developed before silicone oil removal, one rhegmatogenous-RD and three PVR-RDs occurred after, and in two 
patients PVR-RD occurred both before and after silicone oil removal. Two of these seven patients had $\geq 3$ lines increase in vision, one had two lines increase, three remained stable and one had lost two lines in vision before the development of RD. Membrane peeling and repeat silicone oil tamponade were performed. Compared to preoperative VA, at the last examination after RD-repair, six of these seven patients lost more than three lines and only one had three lines visual improvement up to the last examination.

In one patient, a local macular RD developed secondary to a macular pucker before silicon removal. After reattachment, VA improved from $20 / 800$ to $20 / 125$ at the last examination at 17 months after surgery.

In nine patients, postoperative hemorrhages occurred: one suprachoroidal bleeding, seven subretinal and one patient both a subretinal and vitreous hemorrhage. These hemorrhages were self-limiting, except for two that needed surgical intervention; a suprachoroidal bleeding and one caused by a large subfoveal CNV (see above). These hemorrhages occurred between 1 week and 6 months after surgery both in patients with $(n=6)$ or without $(n=3)$ anticoagulant use.

Optic disc atrophy was observed in one patient, and acute glaucoma in five patients. Two of the latter needed peripheral iridectomy. A non-ischemic central retinal vein occlusion occurred in one patient after 8 months. One patient suffered from a retinal artery occlusion after surgery.

Silicone oil had been removed in all patients, typically 3 to 4 months after the first procedure. When removing the silicone oil, some degree of retinal puckering/cellophane maculopathy was present in $90 \%$ ( 76 out of 84 ) of the patients. The ILM was removed in these patients using ICG staining.

\section{Predictors for visual outcome}

ANCOVA analysis revealed a significant correlation between the preoperative CNV classification $(n=68)$, adjusted for preoperative delay, baseline VA, lesion size, and percentage of blood, and the outcome variable: postoperative VA 1 year after surgery defined as $\log$ MAR $(P=0.026)$ or Snellen equivalents $(P=0.014)$; predominantly classic and occult lesions had a significant better prognosis than minimally classic or hemorrhagic ( $\geq 50 \%$ blood) lesions.

There was no significant difference between the four lesion composition groups if the outcome was defined as less than two $(P=0.129)$ or three $(P=0.333)$ ETDRS lines loss 1 year after surgery.

By analyzing the correlation between all preoperative variables (except lesion composition) and visual outcome with ANCOVA, the preoperative VA turned out to be the strongest (but not statistically significant) prognostic factor.

Also, no significant correlation was found when preoperative delay was assessed as intervals of more or less than 4 and 6 (the latter is the median delay) weeks and postoperative visual outcome (defined as ETDRS-VA or less than two or three ETDRS lines loss) at 1 year after surgery.

\section{Discussion}

A free autologous RPE-choroid graft stabilized the mean VA up to 4 years after surgery $(0.74 \log$ MAR, $\Delta=-0.21)$ after $\mathrm{CNV}$ removal in patients with exudative AMD. Despite the occurrence of serious intra- and postoperative complications, such as $8 \%$ retinal detachments (RD), a VA of $20 / 80$ or better was observed up in some patients up to 4 years after surgery. Fixation over the graft was achieved in $74 \%$ of the eyes up to the last examination.

This study did not reveal a significant correlation between preoperative delay, even when analyzed in timeintervals (delay more or less than 4 or 6 weeks). This is surprising, as one would assume that the longer the CNVmembrane would be present beneath the fovea prior to surgical intervention, the more extensive the photoreceptor loss and the less beneficial an RPE-choroid graft would be to visual acuity. We assume that either the number of patients was too small to detect a correlation, or that other variables not included (such as intra-operative variables) acted as confounding factors.

As a predictor for better visual outcome in order to be more selective in patients to treat, predominantly classical membranes were identified in this study as the best candidate, as with photodynamic therapy [34-36]. In the SST-trial, and in studies on full macular translocation, no obvious best candidates were found $[7,12,26]$.

Our functional results compare favorably with two other groups recently reporting on graft translocation in AMD patients, possibly because our $\mathrm{RD}$ rate of $8 \%$ is low compared to theirs of $31 \%$ and $42 \%$ [15, 20]. This difference may be related to a difference in operating technique, as Joussen et al. harvested the graft from the inferior midperiphery. Another possible surgical cause may be our painstaking removal of all remaining hyaloid (which requires visualization by triamcinolon acetonide crystals when working with a chandelier illumination) to prevent remaining hyaloid forming a scaffold for epiretinal membranes. Remarkably, a complete posterior vitreous detachment was rare in these patients.

Our visual results, as well as our rate of $\mathrm{RD}$, also compare favorably with those obtained by simple membrane extraction alone (RD rate of 5-16\%), as demonstrated by the submacular surgery trial (SST) [7, 12]. In full macular translocation, better functional improvements have been described in some reports, but a considerably higher rate of RD may occur $(8-26 \%)[1,2,8,26,28]$. This technique is also more complex and time-consuming compared to the translocation of a free RPE-choroid graft. 
This study also had a better outcome in terms of loss of $\geq 2$ lines and average vision compared with the Photodynamic Therapy (TAP) Investigation and the Verteporfin in Photodynamic Therapy (VIP) Trial, even despite the large size (median $10 \mathrm{DA}$ ) of the lesions we treated with an RPEchoroid graft [34, 36, 37].

However, one has to be careful to compare the results of this extended pilot study to the other treatment modalities that were studied in prospective controlled trials, whereas all surgical approaches (except the SST studies) have been uncontrolled single-center pilot studies.

The free RPE-choroid graft was revascularized in our patients as revealed by the early fluorescence of the graft by FA and the perfused parallel oriented vessels of the graft by ICG (Fig. 4) (Maaijwee et al., unpublished data). This was histologically confirmed in a pig model by demonstration of bridging vessels arising from the underlying recipient layer into the graft and not into the edge of the graft [18]. However, Maclaren et al. reported on one patient with a graft perfused from its periphery by blood entering horizontally through a contact point with the surrounding macular choroid as estimated by high speed angiography [20]. This is plausible, as in skin grafts the major contribution to revascularization of the graft originates from the underlying bed, and also, but less often, from the graft margins $[6,14]$.

Irregular accumulation of hyperpigmentation developed typically from 3 months after surgery onwards, at the margins or beside the graft (in the atrophic area), and increased with time (Fig. 4). RPE wound repair in the elderly probably occurs by cell migration and elongation [33]. We suggest that this hyperpigmentation at the margins of the graft may be explained by a crowding phenomenon of the RPE cells, because the relatively normal Bruch's membrane ends abruptly at the graft's margin. The accumulation of dark pigment in the atrophic area adjacent to the graft might be a reaction to the membrane extraction, and may consist of choroidal melanin as well as remnants of RPE-cells.

MacLaren et al. reported on the long-term ( $\geq 5$ years) function of a free RPE-choroid graft taken from the paramacular area in four patients, with decline in VA in three patients and loss of fixation in all [19]. As OCT suggested loss of photoreceptor outer segments, as was also observed in this study, they hypothesized that this may be explained by chronic photoreceptor apoptosis, initiated by either surgery or the disease process itself [19]. They also warned against unduly optimistic expectations from studies with a shorter follow-up. Nevertheless, several of their findings may be interpreted positively. Firstly, fibrosis and recurrent choroidal membranes were not a major problem, whereas this occurs regularly after laser coagulation, membrane extraction and macular translocation surgery. The recurrence rate in our study was $13 \%$, but is probably underestimated, as angiography was only performed if pathology was clinically suspected. Secondly, if surgical trauma indeed causes photoreceptor damage, less surgical damage might improve the long-term results [17]. In our study, better photoreceptor survival might be expected, as the free graft was taken from the midperiphery, which reduces submacular manipulation, compared to the use of a juxta-foveal site as described by Stanga and MacLaren et al. $[19,32]$.

In fact, at this moment the main challenge is to find a reproducible and safe way to deliver the free graft under the macula in one go without further manipulation. We hypothesize that, with improved instrumentation and subsequent less trauma, the functional results may further improve and enable us to start a controlled trial. With promising pharmaceutical agents like anti-VEGF being developed and available at present, RPE-choroid graft surgery should be perfected and be available as a lastresort option to patients not treatable or no longer responding to approaches with less potential complications.

Financial support The SWOO-Flieringa Foundation (Foundation Scientific Research Eye Hospital Rotterdam), the Rotterdam Eye Hospital, Rotterdam, the Netherlands.

\section{References}

1. Abdel-Meguid A, Lappas A, Hartmann K, Auer F, Schrage N, Thumann G, Kirchhof B (2003) One year follow-up of macular translocation with 360 degree retinotomy in patients with agerelated macular degeneration. Br J Ophthalmol 87:615-621

2. Aisenbrey S, Lafaut BA, Szurman P, Grisanti S, Luke C, Krott R, Thumann G, Fricke J, Neugebauer A, Hilgers RD, Esser P, Walter P, Bartz-Schmidt KU (2002) Macular translocation with $360^{\circ}$ retinotomy for exudative age-related macular degeneration. Arch Ophthalmol 120:451-459

3. Augood CA, Vingerling JR, de Jong PT, Chakravarthy U, Seland J, Soubrane G, Tomazzoli L, Topouzis F, Bentham G, Rahu M, Vioque J, Young IS, Fletcher AE (2006) Prevalence of age-related maculopathy in older Europeans: the European Eye Study (EUREYE). Arch Ophthalmol 124:529-535

4. Binder S, Stolba U, Krebs I, Kellner L, Jahn C, Feichtinger H, Povelka M, Frohner U, Kruger A, Hilgers Rd, Krugluger W (2002) Transplantation of autologous retinal pigment epithelium in eyes with foveal neovascularization resulting from age-related macular degeneration: a pilot study. Am J Ophthalmol 133:215-225

5. Binder S, Krebs I, Hilgers RD, Abri A, Stolba U, Assadoulina A, Kellner L, Stanzel BV, Jahn C, Feichtinger H (2004) Outcome of transplantation of autologous retinal pigment epithelium in agerelated macular degeneration: a prospective trial. Invest Ophthalmol Vis Sci 45:4151-4160

6. Birch J, Branemark PI (1969) The vascularization of a free fullthickness skin graft: I. A vital microscopy study. Scand J Plast Reconstr Surg 3:1-10

7. Bressler NM, Bressler SB, Childs AL, Haller JA, Hawkins BS, Lewis H, MacCumber MW, Marsh MJ, Redford M, Sternberg P 
Jr, Thomas MA, Williams GA, Submacular Surgery Trials (SST) Reasearch Group (2004) Surgery for hemorrhagic choroidal neovascular lesions of age-related macular degeneration: ophthalmic findings: SST report no. 13. Ophthalmology 111:19932006

8. Eckardt C, Eckardt U, Conrad HG (1999) Macular rotation with and without counter-rotation of the globe in patients with agerelated macular degeneration. Graefes Arch Clin Exp Ophthalmol 237:313-25

9. Fujii GY, de Juan E, Sunness J, Humayun MS, Pieramici DJ, Chang TS (2002) Patient selection for macular translocation surgery using the scanning laser ophthalmoscope. Ophthalmology 109:1737-1744

10. Gragoudas ES, Adamis AP, Cunningham ET Jr, Feinsod M, Guyer DR; VEGF Inhibition Study in Ocular Neovascularization Clinical Trial Group (2004) Pegaptanib for neovascular agerelated macular degeneration. N Engl J Med 351:2805-2816

11. Hawkins BS, Bressler NM, Bressler SB, Davidorf FH, Hoskins JC, Marsh MJ, Miskala PH, Redford M, Sternberg P Jr, Thomas MA, Toth CA; Submacular Surgery Trials Group (2004) Surgical removal vs observation for subfoveal choroidal neovascularization, either associated with the ocular histoplasmosis syndrome or idiopathic: I. Ophthalmic findings from a randomized clinical trial: Submacular Surgery Trials (SST) Group H Trial: SST Report No. 9. Arch Ophthalmol 122:1597-1611

12. Hawkins BS, Bressler NM, Miskala PH, Bressler SB, Holekamp NM, Marsh MJ, Redford M, Schwartz SD, Sternberg P Jr, Thomas MA, Wilson DJ; Submacular Surgery Trials Group (2004) Surgery for subfoveal choroidal neovascularization in age-related macular degeneration: ophthalmic findings: SST report no. 11. Ophthalmology 111:1967-1980

13. Heier JS, Antoszyk AN, Pavan PR, Leff SR, Rosenfeld PJ, Ciulla TA, Dreyer RF, Gentile RC, Sy JP, Hantsbarger G, Shamns N (2006) Ranibizumab for treatment of neovascular age-related macular degeneration: a phase I/II multicenter, controlled, multidose study. Ophthalmol 113:633-642

14. Hinshaw JR, Miller ER (1965) Histology of healing splitthickness, full-thickness autogenous skin graft and donor sites. Arch Surg 91:658-670

15. Joussen AM, Heussen FM, Joeres S, Llacer H, Prinz B, Rohrschneider K, Maaijwee KJ, van Meurs J, Kirchhof B (2006) Autologous translocation of the choroid and retinal pigment epithelium in age-related macular degeneration. Am J Ophthalmol 142:17-30

16. Klaver CC, Wolfs RC, Vingerling JR, Hofman A, de Jong PT (1998) Age-specific prevalence and causes of blindness and visual impairment in an older population: the Rotterdam Study. Arch Ophthalmol 116:653-658

17. Maaijwee K, van Meurs JC (2006) Submacular surgery [letter]. Ophthalmology 113:1471-1472

18. Maaijwee KJ, van Meurs JC, Kirchhof B, Mooij NM, Mackiewicz J, Kobuch K, Joussen AM (2006) Histological evidence for revascularization of an autologous RPE-choroid graft in the pig. Br J Ophthalmol 91:546-550

19. MacLaren RE, Bird AC, Sathia PJ, Aylward GW (2005) Longterm results of submacular surgery combined with macular translocation of the retinal pigment epithelium in neovascular age-related macular degeneration. Ophthalmology 112:20812087

20. MacLaren RE, Uppal GS, Balaggan KS, Tufail AD, Munro PM, Ali RR, Aylward GW, Da Cruz L (2007) Autologous transplantation of the retinal pigment epithelium in the treatment of neovascular age-related macular degeneration. Ophthalmology 114(3):561-570
21. Macular Photocoagulation Study Group (1991) Subfoveal neovascular lesions in age related macular degeneration. Guidelines for evaluation and treatment in the Macular Photocoagulation Study. Arch Ophthalmol 109:1242-1257

22. Van Meurs JC, van den Biesen PR (2003) Autologous retinal pigment epithelium and choroid translocation in patients with exudative age-related macular degeneration: short-term follow-up. Am J Ophthalmol 136:688-695

23. Van Meurs JC, ter Averst E, Hofland LJ, van Hagen PM, Mooy CM, Baarsma GS, Kuijpers RW, Boks T, Stalmans P (2004) Autologous peripheral retinal pigment epithelium translocation in patients with subfoveal neovascular membranes. Br J Ophthalmol $88: 110-113$

24. van Meurs JC (2005) Retinal pigment epithelium and choroid translocation in patients with exudative age-related maculopathy. In: Krieglstein GK, Weinreb RN, Kirchhof B, Wong D (eds) Vitreoretinal surgery, essentials in ophthalmology. Springer, Berlin Heidelberg New York, pp 73-87

25. Miskala PH, Bass EB, Bressler NM, Childs AL, Hawkins BS, Mangione CM, Marsh MJ; Submacular Surgery Trials (SST) Research Group (2004) Surgery for subfoveal choroidal neovascularization in age-related macular degeneration: quality-of-life findings: SST report no. 12. Ophthalmology 111:1981-1992

26. Mruthyunjaya P, Stinnett SS, Toth CA (2005) Impact of fluorescein angiographic characteristics of macular lesions on outcomes after macular translocation $360^{\circ}$ surgery in eyes with age-related macular degeneration. Retina 25:597-607

27. Pawlak D, Glacet-Bernard A, Papp M, Roquet W, Coscas G, Soubrane G (2004) Limited macular translocation compared with photodynamic therapy in the management of subfoveal choroidal neovascularization in age-related macular degeneration. Am J Ophthalmol 137:880-887

28. Pertile G, Claes C, (2002) Macular translocation with 360 degree retinotomy for management of age-related macular degeneration with subfoveal choroidal neovascularization Am J Ophthalmol 134:560-565

29. Peyman GA, Blinder KJ, Paris CL, Alturki W, Nelson NC Jr, Desai U (1991) A technique for retinal pigment epithelium transplantation for age-related macular degeneration secondary to extensive subfoveal scarring. Ophthalmic Surg 22:102-108

30. Resnikoff S, Pascolini D, Etya'ale D, Kocur I, Pararajasegaram R, Pokharel GP, Mariotti SP (2004) Global data on visual impairment in the year 2002. Bulletin WHO 82:844-851

31. Rosenfeld PJ, Brown DM, Heier JS, Boyer DS, Kaiser PK, Chung CY, Kim RY; MARINA Study Group (2006) Ranibizumab for neovascular age-related macular degeneration. N Engl J Med 355:1419-1431

32. Stanga PE, Kychenthal A, Fitzke FW, Halfyard AS, Chan R, Bird AC, Aylward GW (2002) Retinal pigment epithelium translocation after choroidal neovascular membrane removal in age-related macular degeneration. Ophthalmology 109:1492-1498

33. Sugino IK, Wang H, Zarbin MA (2003) Age-related macular degeneration and retinal pigment epithelium wound healing. Mol Neurobiol 28:177-94

34. Treatment of age-related macular degeneration with photodynamic therapy (TAP) Study Group (2001) Photodynamic therapy of subfoveal choroidal neovascularization in age-related macular degeneration with verteporfin: two-years results of 2 randomized clinical trials-TAP report No2. Arch Ophthalmol 119:198-207

35. Treatment of age-related macular degeneration with photodynamic therapy and verteporfin in photodynamic therapy study groups (2003) Effect of lesion size, visual acuity and lesion composition on visual acuity change with and without verteporfin therapy for 
choroidal neovascularization secondary to age-related macular degeneration: TAP and VIP report No.1. Am J Ophthalmol 136:407-418

36. Verteporfin in photodynamic therapy (VIP) Study Group (2001) Verteporfin therapy of subfoveal neovascularization in age-related macular degeneration: two-years results of a randomized clinical trial including lesions with occult with no classic choroidal neovascularization-Verteporfin in Photodynamic therapy report 2. Am J Ophthalmol 131:541-560

37. Wormald R, Evans J, Smeeth L, Henshaw K (2005) Photodynamic therapy for neovascular age-related macular degeneration. Cochrane Database Sys Rev 19:CD002030 